\title{
The hospital anxiety and depression rating scale: A cross-sectional study of psychometrics and case finding abilities in general practice Ingrid Olssøn ${ }^{* \dagger 1}$, Arnstein Mykletun ${ }^{\dagger 2,3}$ and Alv A Dahl ${ }^{\dagger 4}$
}

Address: ${ }^{1}$ Department of Psychiatry, Innlandet Hospital HF, Skolegt 32, 2318 Hamar, Norway, ${ }^{2}$ Research Centre for Health Promotion, University of Bergen, 5015 Bergen, Norway, ${ }^{3}$ Norwegian Institute of Public Health, Division of Epidemiology, Department of Mental Health, Oslo, Norway and ${ }^{4}$ Department of Clinical Cancer Research, Rikshospitalet-Radiumhospitalet Trust, 0310 Oslo, Norway

Email: Ingrid Olssøn* - ingrid.olsson@sykehuset-innlandet.no; Arnstein Mykletun - arnstein.mykletun@psyhp.uib.no; Alv A Dahl - alvd@ulrik.uio.no

* Corresponding author †Equal contributors

Published: 14 December 2005

BMC Psychiatry 2005, 5:46 doi:10.1 I86//47|-244X-5-46

This article is available from: http://www.biomedcentral.com/I47I-244X/5/46

(c) 2005 Olssøn et al; licensee BioMed Central Ltd.

This is an Open Access article distributed under the terms of the Creative Commons Attribution License (http://creativecommons.org/licenses/by/2.0), which permits unrestricted use, distribution, and reproduction in any medium, provided the original work is properly cited.
Received: 21 June 2005

Accepted: 14 December 2005

\begin{abstract}
Background: General practitioners' (GPs) diagnostic skills lead to underidentification of generalized anxiety disorders (GAD) and major depressive episodes (MDE). Supplement of brief questionnaires could improve the diagnostic accuracy of GPs for these common mental disorders.

The aims of this study were to examine the usefulness of The Hospital Anxiety and Depression Rating Scale (HADS) for GPs by: I) Examining its psychometrics in the GPs' setting; 2) Testing its case-finding properties compared to patient-rated GAD and MDE (DSM-IV); and 3) Comparing its case finding abilities to that of the GPs using Clinical Global Impression-Severity (CGI-S) rating.

Methods: In a cross-sectional survey study I,78I patients in three consecutive days in September 200 I attended I4I GPs geographically spread in Norway. Sensitivity, specificity, optimal cut off score, and Area under the curve (AUC) for the HADS and the CGI-S were calculated with Generalized Anxiety Questionnaire (GAS-Q) as reference standard for GAD, and Depression Screening Questionnaire (DSQ) for MDE.

Results: The HADS-A had optimal cut off $\geq 8$ (sensitivity 0.89 , specificity 0.75 ), AUC 0.88 and $76 \%$ of patients were correctly classified in relation to GAD. The HADS-D had by optimal cut off $\geq 8$ (sensitivity 0.80 and specificity 0.88 ) AUC 0.93 and $87 \%$ of the patients were correctly classified in relation to MDE. Proportions of the total correctly classified at the CGI-S optimal cut-off $\geq 3$ were $83 \%$ of patients for GAD and $81 \%$ for MDE.
\end{abstract}

Conclusion: The results indicate that addition of the patients' HADS scores to GPs' information could improve their diagnostic accuracy of GAD and MDE.

\section{Background}

An important task for general practitioners (GPs) is to diagnose and treat depressions and anxiety disorders, which are among the most common and amenable mental disorders in their practice [1]. The literature shows that the GPs' diagnostic skills concerning these common disorders are moderately good [1-8], and somewhat better for major depressive episodes (MDE) than for generalized anxiety disorder (GAD) [8]. A prospective cohort study of depression in primary care, found that the WHO-5 well 


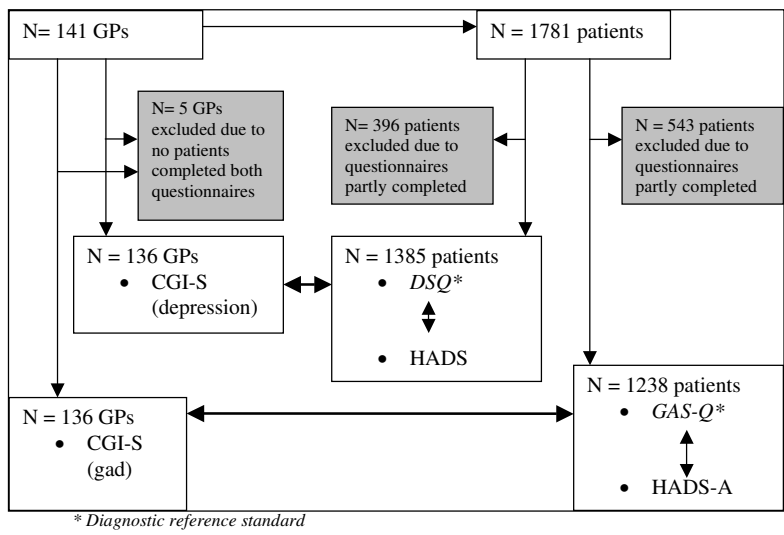

Figure I

Flow chart study design.

being index (WHO-5, 5 items) had significantly higher sensitivity than the GPs' clinical diagnosis when the Composite International Diagnostic Interview (CIDI) was used as gold standard [9]. The depression module of the brief patient health questionnaire (B-PHQ, 9 items) had significantly higher specificity than GPs' clinical diagnoses, and GPs' diagnoses had significantly higher specificity than the WHO-5. The sensitivity and specificity of screening instruments for GAD in general practice has hardly been investigated $[10,11]$.

Reviews [12,13] show that the Hospital Anxiety and Depression Rating Scale (HADS) [14] is widely used as a brief self-rating instrument for both dimensional and categorical aspects of anxiety and depression in both epidemiology and specialist care. In these settings the psychometric properties of the HADS are excellent $[15,16]$. Until now the factor structure, the internal consistency, and the inter-correlation and homogeneity of the HADS sub-scales have not been described in the context of general practice. The case-finding abilities of the HADS in relation to DSM-III/DSM-IV and ICD-10 defined anxiety disorders and depressions by the use of a score $\geq 8$ as cut-off are considered good with few false negatives, but a definite proportion of false positives. In clinical practice a positive screening typically results in further evaluation. Considering the brevity and feasibility of the HADS, it should be useful for screening of patients in general practice, but studies of the HADS from that part of the health services are few and inconsistent as to cut-off scores for caseness [17-20]. These points indicate the need for more data on the case-finding abilities of the HADS subscales in general practice.

\section{Aims of the study}

This study from Norwegian general practice has the following aims: 1) To examine the psychometric features of the HADS rated by patients in the primary care setting; 2 ) To test the case-finding properties of the HADS in relation to the diagnoses of GAD and MDE based on patient-rating of their diagnostic criteria according to DSM-IV as reference standards; and 3) To compare the case finding abilities of the HADS rated by patients to that of GPs using the Clinical Global Impression-Severity (CGI-S).

\section{Methods \\ Procedure}

The study is based on a cross-sectional study of GP's and their patients carried out in Germany, Scandinavia, and Finland $[8,21]$. A flow-chart over the study design is shown in Figure 1. Essential features of the design were: 1) Sampling of GPs geographically spread in Norway; 2) During three consecutive days in September 2001 all the GPs' patients were invited to take part in a study rating themselves on the three questionnaires concerning anxiety and depression;. 3) Blind to the patients' ratings, the GPs filled in the CGI-S in order to rate the clinical severity of eventual GAD and MDE in their patients. Exclusion criteria for patients were: age $<16$ years, language difficulties, patients who required help to complete the questionnaires, and patients who came for prescription only, or for an accident/emergency.

\section{Sampling of GPs}

The GPs in various parts of Norway were recruited as a convenience sample among those registered in the database of Wyeth Norway Ltd. The procedural information to the GPs was given in writing, and no special training of them for the study was undertaken. Among 141 participating GPs, 136 were eligible and 133 gave demographic data. Ninety GPs (68\%) were men and 43 (32\%) women. They had been working in primary care for a mean of 15 (SD 7) and 11 (SD 7) years, respectively, and 118 (89\%) of them worked in group practice. The GPs consulted with a mean of 21.1 (SD 5.1) patients on an average day. There were no significant differences between genders of GPs with regard to number of consultations.

\section{Sampling of patients}

Among the 1,781 patients included in the study, 1,385 (78\%) had valid ratings on the DSQ and the HADS-D, and 1,238 (70\%) on the GAS-Q and the HADS-A. The proportion of women in the two samples was $64 \%$ and $63 \%$, respectively, with a mean age of 45 (SD 17) for women and 50 (SD 17) years for men. Further demographic characteristics of patients are shown in Table 1. The non-complying patients did not differ significantly from the compliers as to age and gender, which were the only data at disposal for attrition analyses. 
Table I: Sample characteristics.

\begin{tabular}{|c|c|c|}
\hline Variables & $\begin{array}{c}\text { DSQ/HADS } \\
\text { sample } N=1,385\end{array}$ & $\begin{array}{c}\text { GAS-Q/HADS } \\
\text { sample } N=1,238\end{array}$ \\
\hline \multicolumn{3}{|l|}{ Age, mean (SD): } \\
\hline Female & $45.7(17.3)$ & $45.2(17.1)$ \\
\hline \multirow[t]{2}{*}{ Male } & $49.8(17.3)$ & $50.0(17.7)$ \\
\hline & $\mathbf{N}(\%)$ & $\mathbf{N}(\%)$ \\
\hline \multicolumn{3}{|l|}{ Gender: } \\
\hline Female & $886(64.0)$ & $783(63.2)$ \\
\hline Male & $499(36.0)$ & $455(36.8)$ \\
\hline \multicolumn{3}{|l|}{ Civil status: } \\
\hline $\begin{array}{l}\text { Married /paired } \\
\text { relationship }\end{array}$ & $934(68.0)$ & $848(68.9)$ \\
\hline Living alone & $440(32.0)$ & $383(3 \mathrm{I} .1)$ \\
\hline \multicolumn{3}{|l|}{ On sick leave: } \\
\hline Yes & $248(20.2)$ & $208(18.9)$ \\
\hline No & $980(79.8)$ & $893(81.1)$ \\
\hline \multicolumn{3}{|l|}{ Prevalence rates: } \\
\hline $\begin{array}{l}\text { DSQ / GAS-Q } \\
\text { positive }\end{array}$ & $125(9.0)$ & $73(5.9)$ \\
\hline $\begin{array}{l}\text { HADS-D / HADS-A } \\
(\geq 8)\end{array}$ & $256(18.5)$ & $357(28.8)$ \\
\hline CGI-S (dep / gad, $\geq 3$ ) & $337(24.3)$ & $217(17.5)$ \\
\hline
\end{tabular}

\section{Diagnostic criteria and instruments}

Psychiatric classification systems like DSM-IV and ICD-10 are based on the presence or absence of various operationalized diagnostic criteria. When structured interviews are used, the patients are asked for the presence of the diagnostic criteria by an interviewer. In contrast, in this study the patients rate themselves the diagnostic criteria for GAD (DSM-IV) on the Generalized Anxiety Questionnaire (GAS-Q) and for MDE (DSM-IV) on the Depression Screening Questionnaire (DSQ), and these patient ratings are used as diagnostic reference standard in this study.

The GAS-Q is a modification of the Anxiety Screening Questionnaire [22], and is a self-rating questionnaire developed to diagnose GAD according to DSM-IV and ICD-10. The GAS-Q consists of 20 items covering the diagnostic criteria for GAD in the DSM-IV. Test-retest reliability of the GAS-Q over a two-day retest period showed a kappa value of 0.74 for the diagnosis of GAD. Congruent validity comparing GAS-Q diagnosis with the DSM IV algorithm for GAD of the Composite International Diagnostic Interview showed a kappa of 0.72 [23].

The DSQ was made for patient-rating of MDE according to DSM-IV and ICD-10 [24] and was chosen as our reference standard. The DSQ is an 11 item questionnaire in which diagnostic criteria are rated on a three point scale, supplemented by three questions to assess the age at first and current episode, and the number of episodes according to the criterion A of MDE in DSM-IV. Consistent with the DSM-IV criteria, a diagnosis of MDE was assigned when at least five of the items were rated as positive by the patient. In the German part of the European study, the internal consistency of the DSQ showed a Cronbach's coefficient alpha of 0.83 [25]. Test-retest reliability over a two-day period found a kappa value of 0.82 for MDE [8]. Tests of the DSQ diagnosis versus diagnosis of MDE based on structured interview showed a kappa 0.89 [26].

The HADS consists of seven items for anxiety (HADS-A) and seven for depression (HADS-D). The items are scored on a four-point scale from zero (not present) to three (considerable). The item scores are added, giving subscale scores on the HADS-A and the HADS-D from zero to 21 . In this study valid HADS subscale scores were defined as having answered at least five of seven items on both the HADS-A and the HADS-D. In order to be valid in patients with somatic problems, the HADS items were based on the psychological aspects of anxiety and depression. The anxiety items were concentrated on general anxiety, and five of the items were close to the diagnostic criteria of GAD. The depression items were based on anhedonia, which is considered to be one of the essential criteria of depression [27]. The concurrent validity of the HADS compared to other questionnaires for anxiety and depression is described between 0.60 and 0.80 for both subscales [13].

The CGI-S is a standardized assessment tool that is widely used as an outcome measure in research [28]. The CGI-S had the following wording: "In your clinical judgement how severely does this patient suffer from MDE/GAD?" The ratings of CGI-S were: $1=$ not ill at all, 2 = a borderline case, 3 = only mildly ill, 4 = moderately ill, 5 = seriously ill and $6=$ extremely seriously ill. The CGI-S scale was dichotomised into $1-2=$ not ill, $3-6=$ ill, but we also explored the frequency of cases by a CGI-S score of $\geq 2$ (= borderline case).

\section{Statistical methods}

The statistical analyses were carried out with the SPSS for Windows, version 11.0. Principal Component Analysis (PCA) with oblique rotation was performed to explore the factor structure of the HADS. Internal consistency of the HADS-A and the HADS-D was tested using Cronbach's coefficient alpha. Pearson's correlation coefficient was used for estimation of the overlap between the subscales. Sensitivity and specificity were calculated for different cutoff values for the HADS-A, the HADS-D, and the CGI-S in relation to the prevalence rate of GAD identified with GAS-Q and the rate of MDE identified with DSQ. Sensitivities and specificities by optimal cut-off were used to cal- 
Table 2: Sensitivity and specificity for HADS-A/D and CGI-S.

\begin{tabular}{|c|c|c|c|c|c|c|c|}
\hline & \multirow[b]{2}{*}{ Score } & \multicolumn{3}{|c|}{$\begin{array}{l}\text { Generalized Anxiety Disorder } \\
\qquad(N=1,238)\end{array}$} & \multicolumn{3}{|c|}{$\begin{array}{l}\text { Major Depressive Episode } \\
\qquad(\mathrm{N}=1,385)\end{array}$} \\
\hline & & $\mathbf{N}(\%)$ & Sensitivity & Specificity & $\mathbf{N}(\%)$ & Sensitivity & Specificity \\
\hline \multirow[t]{10}{*}{ HADS - A/D } & 5 & $637(5 \mid .5)$ & 0.99 & 0.52 & $463(33.4)$ & 0.94 & 0.73 \\
\hline & 6 & $528(42.6)$ & 0.97 & 0.61 & $384(27.7)$ & 0.89 & 0.78 \\
\hline & 7 & $444(35.9)$ & 0.92 & 0.68 & $301(21.7)$ & 0.83 & 0.84 \\
\hline & 8 & $357(28.8)$ & 0.89 & 0.75 & $256(18.5)$ & 0.80 & 0.88 \\
\hline & 9 & $296(23.9)$ & 0.85 & 0.80 & $201(14.4)$ & 0.74 & 0.91 \\
\hline & 10 & $236(19.1)$ & 0.71 & 0.84 & $156(11.3)$ & 0.68 & 0.94 \\
\hline & II & $198(16.0)$ & 0.64 & 0.87 & $118(8.5)$ & 0.61 & 0.97 \\
\hline & 12 & 157 (12.7) & 0.58 & 0.90 & $91(6.6)$ & 0.50 & 0.98 \\
\hline & 13 & $127(10.3)$ & 0.47 & 0.92 & $64(4.6)$ & 0.36 & 0.99 \\
\hline & 14 & $95(7.7)$ & 0.34 & 0.94 & $41(3.0)$ & 0.26 & 0.99 \\
\hline \multirow[t]{5}{*}{ CGI-S } & 2 & $314(25.4)$ & 0.74 & 0.78 & $529(38.2)$ & 0.93 & 0.63 \\
\hline & 3 & $217(17.5)$ & 0.52 & 0.85 & $337(24.3)$ & 0.79 & 0.81 \\
\hline & 4 & $14 \mid(11.4)$ & 0.38 & 0.90 & $208(15.0)$ & 0.64 & 0.90 \\
\hline & 5 & $20(1.6)$ & 0.08 & 0.99 & $29(2.1)$ & 0.14 & 0.99 \\
\hline & 6 & $2(0.2)$ & 0.00 & 1.00 & $2(0.1)$ & 0.02 & 1.00 \\
\hline
\end{tabular}

culate the rates of true and false positive and negative cases. The Receiver Operating Characteristics (ROC-curve) were depicted graphically, and the Area Under the Curve (AUC) were calculated for the HADS-A, the HADS-D and the CGI-S against the GAS-Q and the DSQ as reference standards. The associations of age and gender to caseness on the instruments were examined by logistic regression analyses. All significance tests were two-tailed, and p-values $<.05$ were reported as significant.

\section{Ethics}

The Committee for Medical Ethics of Health Region East of Norway approved this study. The participants delivered informed consent after written information about the study. Wyeth Norway Ltd paid the GPs a fixed sum of EUR 15 per patient in addition to their normal salary. No employees of Wyeth Ltd. were present in any of the general practices during the day of inclusion. The national study leader coordinated the study, and Wyeth Norway Ltd functioned as sponsor of the study. This implied that employees of Wyeth Norway Ltd brought the material for the study to the GPs and later on collected the forms, but otherwise had no active part in the study. The company made no use of the collected data or analyses in their marketing. The study leader and his co-authors had no restrictions as to the content of the publications from Wyeth Norway Ltd, and the company did not want to review any manuscripts before submission.

\section{Results}

Prevalence rates

According to the DSQ, 9.0\% (CI $7.6-10.7 \%$ ) of patients had MDE, and based on the GAS-Q 5.9\% (CI $4.7-7.4 \%$ ) had GAD. Prevalence rates for HAD-D $(\geq 8)$ and HADS-A ( $\geq 8$ ) were $18.5 \%$ (CI $16.5-20.6 \%$ ) and $28.8 \%$ (CI 26.3 $31.5 \%)$, respectively. According to GPs' clinical judgement by CGI-S ( $\geq 3$ ) the prevalence rates were $24.3 \%$ (CI $22.1-26.7 \%$ ) for MDE and 17.5\% (CI 15.5 - 20.0\%) for GAD. The associations between female gender and CGI-S caseness of depression (OR 1.5, $\mathrm{p}=0.004$, CI 1.3-1.9) and HADS-A caseness of anxiety disorder (OR 1.4, $\mathrm{p}=$ 0.013 , CI $1.1-1.8$ ) were both significant. Age significantly reduced the prevalence of caseness with $1-3 \%$ on DSQ, GAS-Q and HADS-A. Based on a GPs' CGI-S score cut-off $\geq 2$, the prevalence rates were $38 \%$ for MDE and $25 \%$ for GAD.

\section{Psychometrics of the HADS}

The internal consistency of the HADS-A and the HADS-D showed coefficient alpha of 0.89 and 0.86 , respectively. PCA with varimax rotation of all 14 HADS items, extracted two factors both with Eigen-value of 4.13 , and that factor solution comprised $59 \%$ of the explained variance. Anxiety and depression items loaded on separate factors. The anxiety and depression sub-scales shared 54\% of the explained variance.

\section{Case-finding abilities of the HADS}

Case-finding abilities for various cut-off values of the HADS-A and the HADS-D are shown in Table 2. By cut-off 


\section{ROC Curve for detecting GAD}

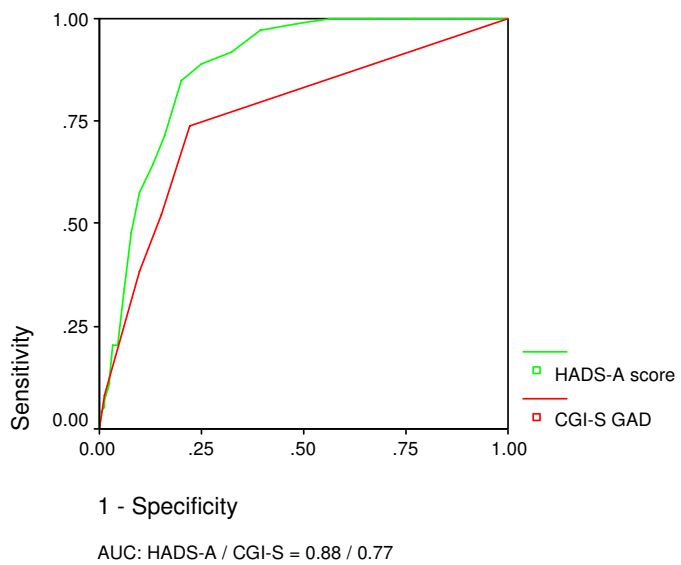

Figure 2

Receiver Operating Curves for HADS-A and CGI-S for detecting GAD.

score of $\geq 8$ on HADS-A, GAD was detected with a sensitivity of 0.89 and a specificity of 0.75 . Using the same cutoff for the HADS-D, MDE cases were detected with a sensitivity of 0.80 and a specificity of 0.88 . Identification of GAD showed an AUC of 0.88 for the HADS-A (Figure 2). For identification of MDE, the AUC was 0.93 for HADS-D (Figure 3).

\section{Comparison of GP-rated and patient-rated case identification}

Using the GPs' CGI-S score of $\geq 3$ as cut-off for a positive diagnosis, GAD was detected with a sensitivity of 0.52 and a specificity of 0.85 (Table 2). MDE was detected with a sensitivity of 0.79 and specificity of 0.81 by the same CGI$S$ cut-off level. Identification of GAD and MDE with the CGI-S showed AUCs of 0.77 (Figure 2) and 0.87 (Figure 3), respectively.

Based on the sensitivities and specificities of the HADS-A by cut-off $\geq 8$ and the CGI-S by cut-off $\geq 3$ (Table 3 ) we found that the true positive disorder rate for the HADS-A $(5.3 \%)$ was close to reference standard (5.9\%) and significantly better than for the CGI-S (3.1\%). The opposite was found for the rates of true positive healthy cases. The total true hit rate of GAD and non-GAD was significantly better for the GP-rated CGI-S (83\%) than for the patient-rated HADS-A (76\%).

For MDE no significant difference was observed between rates of true positive disorder (Table 3). For true nondepression rate, the HADS-D (80\%) showed a significantly better hit rate than the CGI-S (74\%). The proportion of totally right classified depressed patients was
ROC Curve for detecting MDE

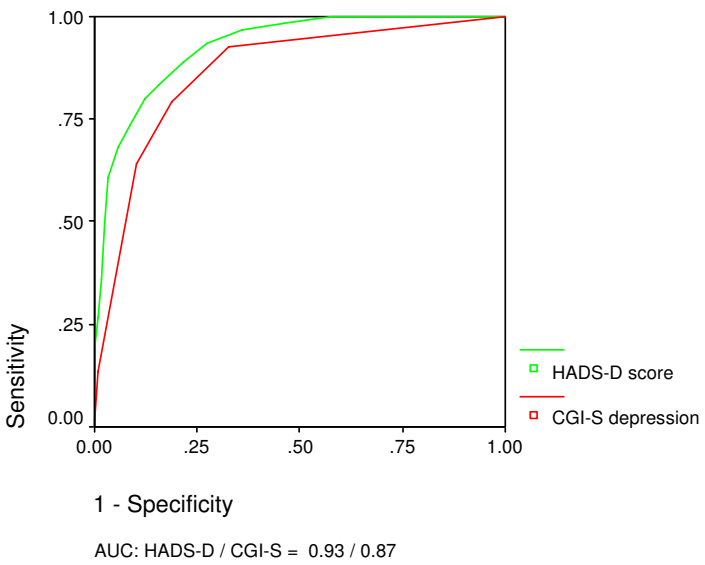

Figure 3

Receiver Operating Curves for HADS-D and CGI-S for detecting MDE.

significantly better for the patient-rated HADS-D (87\%) than for the GP-rated CGI-S (81\%).

\section{Discussion}

\section{Strengths and limitations}

Compared to former studies from general practice the high number of patients and GPs in our study is a strength due to increased variance and reduced biases. The big sample sizes and a responder-rate above 70\% among patients give adequate statistical power to the performed analyses. Our sample consists of geographically spread GPs who's working experience and gender distribution is representative for GPs in Norway [29]. Patients' age and gender is representative for patients attending GPs in Scandinavia [30]. We also consider as a strength that the GPs were blind to the HADS scores of the patients when they made their diagnostic evaluations.

It is a weakness of our study that we did not employ structured interviews for the establishment of reference standard diagnoses of GAD and MDE. However, the reference standards used by us comprise the same diagnostic criteria, are well described, and have shown good validity in relation to structured interviews $[23,25]$. When both the HADS and the reference standards are self-rating instruments, the HADS might be systematically biased with falsely high sensitivity and/or specificity in relation to the reference standard. On the other hand, an interview could introduce observer bias in the interpretation of symptoms, which is eliminated using self-ratings. The reference standard questionnaires used in our study gave prevalence rates for GAD and MDE in general practice that were in accordance with the prevalence rates reported by Üstün \& 
Table 3: Classification of patients with eventual GAD and MDE.

\begin{tabular}{|c|c|c|c|c|}
\hline \multirow[b]{2}{*}{ Sensitivity / Specificity } & \multicolumn{2}{|c|}{$\begin{array}{c}\text { Generalized Anxiety Disorder (GAS-Q Positive } \\
73 / 1,238=5.9 \% \text { ) }\end{array}$} & \multicolumn{2}{|c|}{$\begin{array}{l}\text { Major Depressive Episode (DSQ Positive I25/ } \\
\qquad,, 385=9.0 \% \text { ) }\end{array}$} \\
\hline & $\begin{array}{c}\text { Patients' HADS-A } \geq 8 \\
0.89 / 0.75\end{array}$ & $\begin{array}{l}\text { GPs' CGI-S } \geq 3 \\
0.52 / 0.85\end{array}$ & $\begin{array}{c}\text { Patients' HADS-D } \geq 8 \\
0.80 / 0.88\end{array}$ & $\begin{array}{l}\text { GPs' CGI-S } \geq 3 \\
0.79 / 0.8 \text { I }\end{array}$ \\
\hline Classification & $\%(95 \% \mathrm{Cl})$ & $\%(95 \% \mathrm{CI})$ & $\%(95 \% \mathrm{CI})$ & $\%(95 \% \mathrm{Cl})$ \\
\hline True positive disorder & $5.3(4.1-6.5)^{*}$ & $3.1(2.1-4.1)$ & $7.2(5.8-8.6)$ & $7.1(5.7-8.5)$ \\
\hline False positive disorder & $23.5(21.1-25.9)^{*}$ & $14.1(12.2-16.0)$ & $10.9(9.3-12.5)$ & $17.3(15.3-19.3)^{*}$ \\
\hline Observed disordered & $28.8(26.3-31.3)^{*}$ & $17.2(15.1-19.3)$ & $18.1(16.1-20.1)$ & $24.4(22.1-26.7)^{*}$ \\
\hline True positive healthy & $70.6(68.1-73.1)$ & $80.0(77.8-82.2)^{*}$ & $80.1(78.0-82.2)^{*}$ & $73.7(71.4-76.0)$ \\
\hline False positive healthy & $0.6(0.2-1.0)$ & $2.8(1.9-3.7)^{*}$ & $1.8(1.1-2.5)$ & $1.9(1.2-2.6)$ \\
\hline Observed healthy & $71.2(68.7-73.7)$ & $82.8(80.7-84.9)^{*}$ & 81.9 (79.9-83.9)* & $75.6(73.3-77.9)$ \\
\hline Total rightly classified & $75.9(73.5-78.3)$ & $83.1(81.0-85.2)^{*}$ & $87.3(85.5-89.1)^{*}$ & $80.8(78.7-82.9)$ \\
\hline Total wrongly classified & $24.1(21.7-26.5)^{*}$ & $16.9(14.8-19.0)$ & $12.7(10.9-14.5)$ & $19.2(|7.1-2| .3)^{*}$ \\
\hline
\end{tabular}

*The difference shows a statistical significance of $p \leq 0.05$

Sartorius [1], and this added some validity to our approach. Our design did not take into account the GPs' knowledge about the patients' somatic symptoms or psychosocial situation, which could be relevant information for the GPs in their diagnostic considerations. However, studies have shown that in non-clinical samples chronic somatic problems [16] and demographic variations [31] have only modest influence on the HADS scores.

The use of the CGI-S as a diagnostic instrument could be discussed since the instrument only evaluates the severity of the case. Severity is not a clear concept, and it is implicit in such ratings that the GPs are familiar with both mild and severe cases of GAD and MDE, although that hardly is the case. Further, the GPs could be biased in direction of false positive diagnoses since they took part in a sponsored study concerning these mental disorders.

\section{Comparison with existing literature}

The internal consistency of the HADS was found in accordance with other studies $[16,13]$. The replication of the original two-factor structure of the HADS among primary care attenders has been discussed. A Dutch validation study [32] found evidence for the original two-factor structure among a sample $(\mathrm{n}=112)$ of consecutive general practice patients. Data from a large non-clinical population give support to a s two-factor-structure of the HADS [16] in sub-samples with higher mental symptom levels than in the general population. In our sample from general practice, the HADS showed good separation of items, moderate inter-correlation, and a distinct two-factor structure. These results support the robustness of the HADS as a psychometrically adequate self-rating instrument for patients attending general practice.

An optimal balance between sensitivity and specificity is requested of a good questionnaire. From a clinical per- spective high sensitivity might be seen the most important concern for a screening instrument, giving minimal number of false negative cases at the sacrifice of some false positive cases.

In general we found that the patient-rated HADS-A/D had better diagnostic ability than CGI-S rated by GPs (Figure 2 and 3 ) in relation to GAD and MDE. However, taking into regard the prevalence rate of $5.9 \%$ of GAD in general practice, the GPs' ability to recognise people not suffering from GAD (Table 3 ) is significant superior to that of the HADS-A and important in the clinical setting. With a prevalence rate of $9 \%$ for MDE in general practice the total proportion of patients correctly identified by HADS-D was significantly higher than that of GPs using the CGI-S.

\section{Implications for future research or clinical practice}

HADS showed satisfying psychometric properties in the general practice setting, which is of importance for future research. We found that GPs mainly recognized GAD by exclusion and MDE by inclusion, but still they had a considerable proportion of misclassifications. GPs' diagnostic precision in clinical practice is improved by supplementing HADS scores. The advantage of HADS is its feasibility of completion and well-established cut-off scores for clinically relevant caseness.

\section{Conclusion}

The psychometrics of the HADS was found to be excellent in this sample from general practice. The recommended cut-off score for caseness on the HADS-A and the HADS$\mathrm{D}$ of $\geq 8$ seemed appropriate for detecting GAD and MDE among patients attending primary care. In regard to prevalence rates, the GPs should positively trust their sensitivity in diagnosing MDE, and their specificity in diagnosing GAD by exclusion of patients without anxiety. Patient- 
rated HADS could represent a useful supplement to GPs' own clinical judgment.

\section{Competing interests}

Wyeth Norway Ltd may gain financially from the publication of this manuscript. The manuscript concerns the prevalence and under identification of GAD in primary care, for which Wyeth Norway Ltd. sells venlafaxine $\left(\right.$ Efexor $\left.^{\circledR}\right)$. We have no financial interest to declare.

\section{Authors' contributions}

The authors have carried out the study together. IO organised and analysed data and wrote the first draft of the article. AM contributed to the analyses and the interpretation of the data and constructed the graphs. AAD made contributions to conception and design and revised the manuscript critically.

\section{Acknowledgements}

Hospital Innlandet Trust, Division Psychiatry supported the study. We thank patients and general practitioners contributing to the study and Wyeth Norway Ltd for getting the material to our disposal.

\section{References}

I. Üstün TB, Sartorius N: Mental illness in general health care. Chichester: Wiley; 1995.

2. Goldberg D, Steele JJ, Johnsen A, Smith C: Ability of primary care physicians to make accurate ratings of psychiatric symptoms. Arch Gen Psychiatry 1982, 39:829-33.

3. Jencks SF: Recognition of mental distress and diagnosis of mental disorders in primary care. JAMA 1985, 253:1903-7.

4. Feinstein RE, Brewer AA, Editors: Primary care psychiatry and behavioral medicine. New York: Springer; 1999.

5. Munk-Jørgensen P, Fink P, Brevik JI, Dalgard OS, Engberg M, Hansson L, Holm M, Joukamaa M, Karlsson H, Lehtinen V, Nettbladt P, Stefansson C, Sørensem L, Jensen J, Borgquist L, Sandanger I, Nordström G: Psychiatric morbidity inn primary public health care: a multicentre investigation. Part II. Hidden morbidity and choice of treatment. Acta Psychiatr Scand 1997, 95:6-12.

6. Kessler RC: The epidemiology of pure and comorbid generalized anxiety disorder: a review and evaluation of recent research. Acta Psychiatr Scand Suppl 2000:7-13.

7. Olfson M, Marcus SC, Druss B, Elinson L, Tanielian T, Pincus HA: National trends in the outpatient treatment of depression. JAMA 2002, 287:203-9.

8. Wittchen HU, Kessler RC, Beesdo K, Krause P, Höfler M, Hoyer J: Generalized anxiety and depression in primary care: prevalence, recognition, and management. J Clin Psychiatry 2002, 63(Suppl 8):24-34.

9. Henkel V, Mergl R, Kohnen R, Maier W, Möller HJ, Hegerl U: Identifying depression in primary care: a comparison of different methods in a prospective cohort study. BMJ 2003, 326:200-20I.

10. Hoyer von J, Krause P, Höfler M, Beesdo H, Wittchen HU: When and how well does the family physician recognize generalized anxiety disorders and depressions? Fortschr Medizin 200I, I I 9(Suppl I):26-35. (in German)

II. Beesdo K, Krause P, Höfler M, Witchen HU: Do primary care physicians know generalized anxiety disorders? Estimations of prevalence, attitudes and interventions. Fortschr Medizin 200I, I I9(Suppl I): 13-16. (in German)

12. Herrmann C: International experiences with the hospital anxiety and depression scale - a review of validation data and clinical results. J Psychosom Res 1997, 42:17-41.

13. Bjelland I, Dahl AA, Haug TT, Neckelmann D: The validity of the hospital anxiety and depression scale. An updated literature review. J Psychosom Res 2002, 52:69-77.
14. Zigmond AS, Snaith RP: The hospital anxiety and depression scale. Acta Psychiatr Scand 1983, 67:361-70.

15. Moorey S, Greer S, Watson M, Gorman C, Rowden L, Tunmore R, Robertson B, Bliss J: The factor structure and factor stability of the hospital anxiety and depression scale in patients with cancer. Br J Psychiatry I991, I 58:255-259.

16. Mykletun A, Stordal E, Dahl AA: Hospital anxiety and depression (HAD) scale: factor structure, item analyses and internal consistency in a large population. $\mathrm{Br} J$ Psychiatry 200I, I 79:540-544

17. EL Rufaie $\mathrm{OE}$, Absood $\mathrm{GH}$ : Retesting the validity of the arabic version of the hospital anxiety and depression (HAD) scale in primary heath care. Soc Psychiatry Psychiatr Epidemiol 1995, 30:26-31.

18. Lam CL, Pan PC, Chan AW, Chan CY, Munro C: Can the hospital anxiety and depression (HAD) scale be used on Chinese elderly in general practice? Family Pract 1995, I 2: I49-154.

19. Wilkinson MJ, Barczak P: Psychiatric screening in general practice: comparison of the general health questionnaire and the hospital anxiety depression scale. J Royal Coll Gen Practit 1988, 38:3|I-3|3

20. Löwe B, Spitzer RL, Gräfe K, Kroenke K, Quenter A, Zipfel S, Buchholz $C$, Witte S, Herzog W: Comparative validity of three screening questionnaires for DSM-IV depressive disorders and physicians diagnoses. J Affect Dis 2004, 78: 131-140.

21. Allgulander C, Nilsson B: A nationwide study in primary health care. One out of four patients suffers from anxiety and depression. Lakartidningen 2003, 100:832-838. (in Swedish)

22. Wittchen $\mathrm{HU}$, Boyer $\mathrm{P}$ : Sensitivity and specificity of the anxiety screening questionnaire (ASQ-15). $B r J$ Psychiatry 1998, 173(Suppl 34): 10-17.

23. Krause P, Wittchen HU, Höfler M, Winter S, Spiegel B, Pfister $H$ : Generalisierte angst und depression in der allgemeinartztpraxis (GAD-P). Fortschr Medizin 200I, I I 9(suppl I):5-12

24. Winter S, Wittchen HU, Höfler M, Spiegel B, Ormel H, Müller N, Pfister H: Design und metoden der studie "Depression 2000". Fortschr Medizin 2000, I I 8(suppI I): I I-2I.

25. Höfler M., Wittchen HU: Why do primary care doctors diagnose depression when diagnostic criteria are not met? Int J Methods Psychiat Res 2000, 9:110-120.

26. Wittchen HU, Höfler M, Meister W: Prevalence and recognition of depressive syndromes in German primary care settings: poorly recognized and treated? Int Clin Psychopharmacol 200I, 16:121-135.

27. Watson D, Clark LA, Weber K, Assenheimer JC, Strauss ME, McCormick RA: Testing a tripartite model: II. Exploring the symptom structure of anxiety and depression in student, adult, and patient samples. J Abnorm Psychol 1995, 104:15-25.

28. Guy W: Clinical global impressions scale. ECDEU assessment manual for psychopharmacology. In US Dept Health, Education, and Welfare publication (AMD) 76-338 Rockville, Md: National Institute of Mental Health; 1976:221-227.

29. Statistics and research on physicians in Norway [http:// www.legeforeningen.no/]

30. Engstrom $S$, Foldevi $M$, Borgquist $L$ : Is general practice effective? A systematic literature review. Scand J Prim Health Care 200I, 19:131-144

31. Crawford JR, Henry JD, Crombie C, Taylor EP: Normative data for the HADS from a large non-clinical sample. $\mathrm{Br} J$ Clin Psychol 200I, 40:429-434.

32. Spinhoven PH, Ormel J, Sloekers PPA, Kempen GI, Speckens AE, Van Hemert AM: A validation study of the hospital anxiety and depression scale (HADS) in different groups of Dutch subjects. Psychol Med 1997, 27:363-370.

\section{Pre-publication history}

The pre-publication history for this paper can be accessed here:

http://www.biomedcentral.com/1471-244X/5/46/pre pub 